\title{
Ideal and Rationality of Revitalizing Tourism in the Post-epidemic Era
}

\author{
Pei $\mathrm{Li}^{1}$ \\ ${ }^{1}$ School of Tourism, Northwest Normal University, Lanzhou City, Gansu Province, China
}

\begin{abstract}
The epidemic of COVID-19 has brought a great impact on the global economic development. Tourism, which is highly sensitive and dependent on the environment, has suffered heavy losses and faces a crisis. With the control of the epidemic and the recovery of production, traveling has gradually returned to the public life. The current situation confronting tourism should be considered and managed rationally, and it is urgent and necessary for tourism enterprises to seek opportunities and breakthroughs during the post-epidemic era. The nature of tourism determines that it carries the public's yearning for quality life and the mission of cultural exchange and inheritance, which is also the foundation of the existence of tourism industry. Revitalization of tourism should follow the general rules of industrial development and insist on green, healthy and sustainable development, in addition to that, recognize the situation clearly, seize the opportunities, cultivate new business forms and comprehensive tourism talents, expand new tourism functions, so as to promote the all-round development of economy and society through industrial integration.
\end{abstract}

\section{Difficulties and Opportunities of Tourism Industry under Epidemic Situation}

\subsection{Crisis and difficulties}

At the beginning of 2020, a pneumonia epidemic with novel coronavirus suddenly broke out. Chinese government responded promptly and halted all the travel business from travel agencies and online travel enterprises across the country to curb the spread of the epidemic. Subsequently, airlines, hotels, scenic spots, railways and other involved industries responded to the government's call by cancellation or refund to minimize the loss of tourists. The whole tourism industry came to a standstill. We have to confront the full impact of the epidemic on tourism while we are moved by the scene----all walks of life are working together to fight the epidemic. Tourism, as a comprehensive industry, will be affected by every market segment, such as catering, accommodation, sightseeing, shopping, entertainment, transportation and so on. Undoubtedly, all the factors in tourism have been hit hard by the epidemic. The tourism business suffered extensive damage, including hotel business, outbound travel business, surrounding travel business, air ticket business, scenic spot ticket business and high speed rail travel business. They are presented as follows in Fig.1[1].

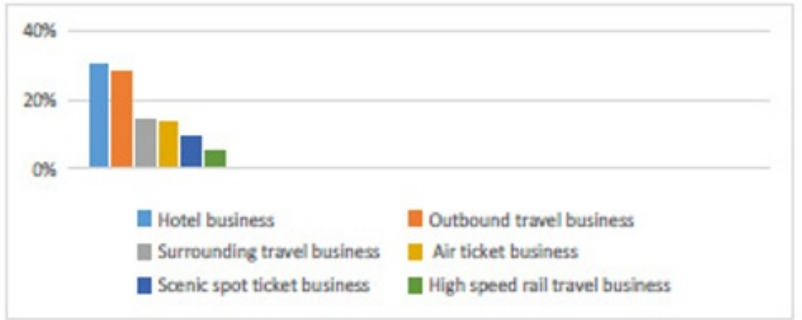

Fig1. Damage to the Tourism Business

As shown in Fig.2[1], the hospitality industry has been most impacted by the epidemic, with the hotel occupancy rate and total revenue falling by more than $20 \%$.

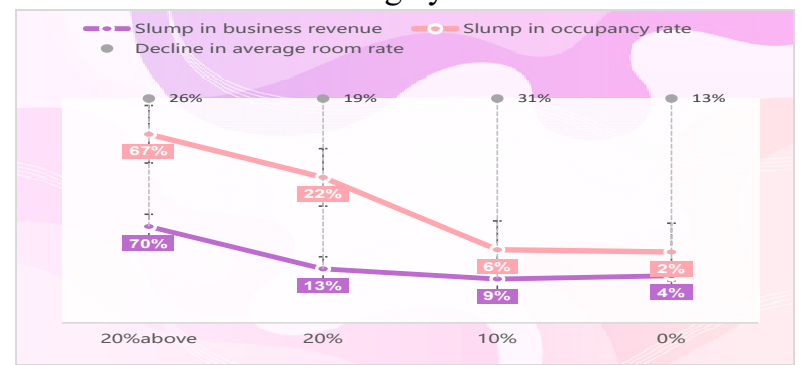

Fig2. Damage to Hotel Business

Tourism enterprises bear the brunt of heavy losses, which are characterized by a slump in business volume and revenue, inability to serve customers normally, cash flow crisis and inability to manage normally, as below in Fig. 3[1]. 


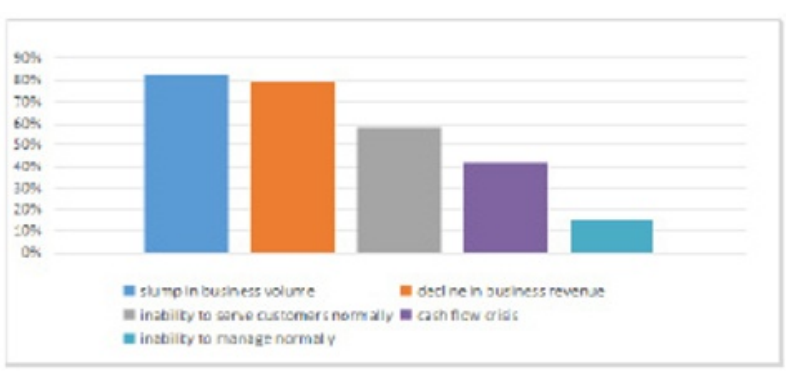

Fig3. Crisis Encountered by Tourism Enterprises

With the worldwide spread of COVID-19, World Health Organization has defined it as a "global pandemic" and a "a global public health emergency". A lot of countries have taken preventive measures such as entry restriction, home quarantine, closure of public places and tourist attractions. Tourism industries around the world have suffered heavy losses. Tourism has been one of the most affected industries according to a recent report released by World Tourism Organization. The report predicts that the number of international tourists will decrease by $70 \%$ if countries gradually open their borders and relax travel restrictions in early September, and tourism income will cut down by 910 billion to 1200 billion US dollars[2].

\subsection{Challenge and opportunities}

Crisis and opportunity always co-exist, and crisis always breeds a turning point. On the one hand, the epidemic has brought a great shock to the tourism industry. On the other hand, it will accelerate industrial upgrading and transformation. As far as the supply-side is concerned, the epidemic pressed the pause button for tourism industry suddenly, which also provided an opportunity of improving themselves. Tourism enterprises are forced to reduce management costs and adjust their market strategies, and they urgently need to find new business and new growth points. Hence, the industrial system of tourism will be optimized, both products and services will be innovated, so that the supply ability will be improved. Nowadays tourism industry has gradually changed into an industry involving multi-factors---capital, intelligence and labor from a labor-intensive industry. Generally, the industrial development follows a rule---increment adjustment in the good times and stock adjustment in the hard times [3]. Therefore, the epidemic will bring a baptism to the development of tourism in the long term, characterized by the following signs: small and mediumsized enterprises will face a reshuffle, and industry giants will wait for the opportunities of mergers and acquisitions. The investment scale of the industry will continue to expand, the industrial chain will be extended, the market will be further subdivided, the industrial integration will be accelerated, capital and talents will gather, which will trigger more innovations with market value, give birth to new incremental markets and investment opportunities, and the product system will be completed. Some opportunities are listed as below in Fig.4[1].

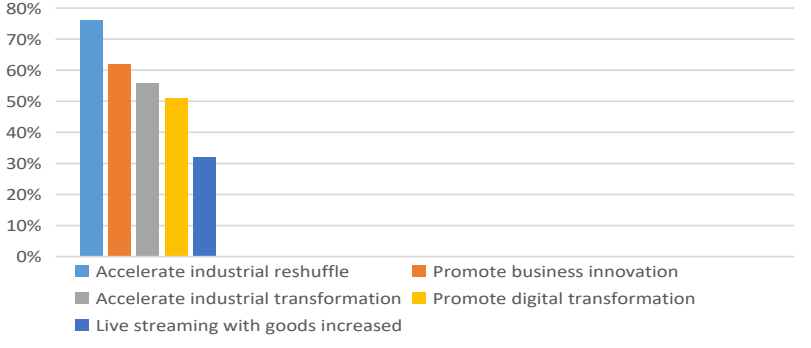

Fig4. Challenges and Opportunities for the Development of Tourism Industry

\section{Ideal and Mission of Tourism}

\section{1 the Public's Yearning for Quality Life}

The rapid development of global tourism and the arrival of mass tourism era, not only show that tourism has become a new impetus to global economic development, but also show that tour has been an important part of people's life and a way of life. City-dwellers can relieve work pressure, release anxiety as well as get relaxed and positive energy through traveling. In this sense, tourism is an industry related to the quality of life, dreams, growth and human happiness. Happiness is the eternal pursuit of human beings, and it is a complicated experience from sensory enjoyment to spiritual pleasure. Studies have shown that travel experience can make people feel life is fulfilling, enriches their perception and understanding of life, makes people love nature more, and enlighten them to be grateful for life. Traveling can get rid of people's negative emotions in work, help them form positive working attitudes, thus they can create good working relationships and atmosphere so as to work effectively. Tour is also something about growth. People can perceive the world and explore the unknown by traveling, which will improve their understanding of the outside world and others, thus gain the spiritual growth. All in all, tour is one of the most important spiritual consumption process in people's life, and it is also an important way for people to improve their quality of life, and brings people another life meaning besides hard work. Since tourism carries the public's yearning for high-quality life, it becomes the vision and mission of China's tourism industry to make it a happy industry. Tourism enterprises should consider firstly how to improve people's sense of happiness and practice the concept of happiness in tourism product exploitation, service provision and marketing promotion. The government should aim to improve gross national happiness and try to provide a good environment and policy guarantee for people's traveling, create a benign platform for the development of tourism enterprises, and make tourism a truly happy industry. Traveling is a basic right of human beings and an important way for human beings to realize their spiritual liberation[4]. 


\subsection{Cultural Inheritance and Exchange}

Tour means that people travel to an unfamiliar place from his usual residence in order to experience different life. Essentially, people seek for a kind of differentiated life experience from their own by traveling. Actually, there are fewer and fewer distinctive tourism resources after decades of rapid development of tourism. With the upgrading of tourist consumption, tourists are no longer only content with enjoying natural scenery, they are eager to appreciate local culture and achieve another kind of life experience by comparing cultural differences. To some extent, culture is the soul of tourism and tourism is the carrier of culture. Tourists are experiencing the local culture during the tour, at the same time they are carrying their culture to the host community. And a new culture may be produced in the exchange of two or more cultures. The integration of culture and tourism not only enables culture to be passed down, protected and spread more widely, but also makes culture produce economic values, besides its social benefits. It is necessary and inevitable to upgrade its products for the development of any industry, tourism is also no exception. Therefore, modern tourism products need to enhance their cultural connotation, tourism enterprises must rely on cultural creativity to highlight the characteristics and differences of tourism resources and create new life scenes and quality experience for more and more fastidious tourists in the future. Tourism based on culture is not subject to natural resources, to some extent, and it can be created by integrating various elements, such as the creation of atmosphere, the design of theme activities and the exertion of imagination.

China has a long history, and is rich in splendid cultural resources----ruins, historical legends, folk customs---which can be tapped for research and development of tourism products. We can exert creativity and imagination on them to develop tourism products which are truly close to people.

\subsection{Industrial Integration and Structural Adjustment}

The development of tourism is no longer limited to the traditional modes---hotels, travel agencies, tourist attractions, theme parks. More and more new tourism modes are emerging such as OTA(online travel agency), tourism planning agencies, tourism consulting companies, tourism real estate, tourism marketing and promotion, self-driving tour bases, tour leisure clubs. The change of tourism modes indicates that the tourism industry is in the process of transformation and upgrading, and also indicates the arrival of the "grand tourism" era, which is inevitable when the development of tourism is entering a mature stage. With the greater diversity of tourism demands, the tourism industrial chain continues to extend, forming a "tourism plus"mode with high industrial relevance and comprehensive benefits. Tourism has greatly broken through the traditional business scope at this stage, widely involved and integrated with other industries, such as agriculture, sports, education, medical care, science and technology, ecology, real estate and other fields----forming an industrial cluster, which drives the development of regional economy. For example, rural tourism, which combines tourism with agriculture, has become an effective way to revitalize rural economy, increase farmers' income and improve rural environment. Ecotourism combines tourism with ecology to produce a "win-win" situation of economic development and ecological civilization by building forest parks, wetland parks, desert parks in poverty-stricken areas, strengthening the construction of tourism supporting facilities such as nature reserves, grasslands and mountains, and creating new tourism forms such as ecological scientific research and ecological health care. The integration of tourism and sports can create health and sports tourism. We can make use of mountains, canyons, water resources and other landform resources to develop health and sports products such as mountain sports, water sports, outdoor training, outdoor camping, extreme sports and hiking adventure, which will deepen the industrial integration of sports, tourism, leisure, fitness, festivals and events.

\section{Rational Thought and Choice of Revitalizing Tourism}

At present, the trend of the epidemic is still unknown and variable although it has been effectively controlled, and epidemic prevention has become normal. The world affected by the epidemic is undergoing profound changes and facing many uncertain and unstable factors. In my opinion, it is our proper attitude towards life to stay rational in the post-epidemic era.

Tour has gradually returned to our daily life. People are eager to get close to nature after several months' home quarantine. People's yearning and pursuit for a better life is always the foundation and goal of the tourism industry. In addition, the interdisciplinary feature of tourism can lead to wider economic and social recovery. It is blind to pin the hope of revitalization on rebound, and we should judge the current situation calmly and make some choices rationally.

\subsection{Insist on the Principle of Healthy, Green and Sustainable Development}

People's health is closely connected with and affected by ecological environment and climate change. Throughout the history of human epidemic, all disasters originated from human beings' wrong treatment to nature. The outbreak of COVID-19 is another warning to human beings from nature, and it reminded us to reflect on our behavior. It is worth thinking deeply for us how to keep the harmony between mankind and nature in the highly industrialized and urbanized society? We must realize that no matter how we utilize and remake nature, we should not violate the principle of healthy, green and sustainable development and deal with properly the relations between nature and man-made. So the exploitation of tourism resources should be based on ecological protection. The choice of resources should follow the pattern of "ecology plus" tourism, we can rely on the good climate and 
ecological environment to create ecological experience tour, holiday and health tour, hot spring spa and health tour, forest and health tour, island and health tour, lake and health tour, mountain and health tour, farmland and health tour, and to produce leisure farms, health resorts, health valleys, ecological hotels, feature towns, which will form a comprehensive ecological health industry. As far as the planning of the entertainment venues, shopping spots, exhibition halls and other spaces is concerned, it is necessary to consider the design of artificial corridors and walking greenways. The layout of space should be scattered appropriately to avoid excessive gathering of tourists and ensure fresh air flow. Consider that consumers will pay more attention to their health after the epidemic, catering must be strictly supervised in food selection, processing, packaging and dining environment.

\subsection{Cultivate New Tourism Modes, Expand Tourism Functions}

The outbreak of the epidemic forced tourism industry to upgrade, and forced all market entities to innovate. After the epidemic, the tourism industry should focus on the changes of tourists' needs, make every effort to innovate and upgrade tourism elements, guide tourism consumption and create new business types in a planned way. From the perspective of "grand tourism", new tourism modes mean "tourism plus" modes of industrial integration, which will expand the business boundary of tourism enterprises in an all-round way through crossover cooperation, enrich the categories of tourism products, penetrate every field of people's life, and meet people's needs of different levels. In fact, so-called "grand tourism" covers the first, the second and the third industry, involving both life and production, so it can make a series of traditional industries get revitalized, such as agricultural and fruit industry, lake industry, hot spring industry, exhibition industry, cultural industry, ecological industry, sports industry and medical industry, which will make use of the advantages of the tourism market, so as that the industrial system will be innovated, new opportunities will be created, tourism functions will be expanded.

People will pay more attention to the health and safety during the traveling, so quality products and services will be favored. It is worth noting that the tourism industry needs to redefine the technology empowered tourism market with $5 \mathrm{G}$, artificial intelligence, virtual reality, and big data which have been involved in young people's cultural life and leisure time deeply and widely. Investment and operation of scenic spots and theme parks are increasingly dependent on technology and culture. Enterprises without technological investment and ability to research new projects and products have no future in the process of industrial evolution.

\subsection{Establish Crisis Response Mechanism to Enhance Anti- risk Ability of Tourism}

The outbreak of COVID-19 brought the tourism industry to a standstill, so tourism practitioners must realize the sensitivity and dependence of the tourism industry on the environment and develop a sense of crisis in order to prepare themselves for risks in advance, to improve their ability to resist risks, so that they can respond promptly and accurately in case of public emergency. At present, Chinese government sector, as the most important subject of governance, takes the main responsibility of public crisis management. All kinds of tourism associations and enterprises should also play their roles in a crisis under government's guidance. They should recognize promptly the situation, explore actively countermeasures to minimize losses and reduce negative impacts when a crisis occurs. Tourism enterprises should show a sense of social responsibility and establish a good industrial image to maintain tourists' confidence. In addition, it is necessary to keep the continuity and unity of information transmission in the process of crisis management, provide updated information, know when to speak and when to keep silent, and choose to announce the different stages of crisis management at appropriate time nodes, so as to know tourists' response without delay. It is also important to realize that crisis can be turned into opportunity. For instance, it is wise for tourism enterprises to conduct online-training for their employees to reserve talents and strengthen product research and development during the epidemic, promote tourism products with market potential and try diversified operation modes in the recovery stage of tourist market.

\section{4 conclusion}

Tourism practitioners are eager to get out of present difficulties brought by the epidemic. Revitalizing tourism not only means the recovery of tourism industry, but also involves the improvement of gross national happiness index, the exchange and inheritance of national culture, the protection and improvement of ecological environment and the development of regional economy. Although the recovery of tourism can be expected in the near future, the tourism demands will change with the normalization of epidemic prevention and control. People will pay more attention to the quality and individualization of tourism products after the epidemic. Accordingly, the tourism industry also needs to build a new normal, demand--oriented tourism service system and tourism consumption chain. The rationality of revitalizing tourism means not pursuing short-term economic benefits at the cost of the environment, but adhering to the green and healthy principles to achieve sustainable development. It means an attitude of dealing with a crisis calmly. It also means making proper judgment and choice.

\section{References}

1. Data source:An investigation report on the epidemic situation of China's tourism industry in 2020.https://www.traveldaily.cn (TravelDaily)

2. UNWTO World Tourism Barometer, released by UNWTO on May 7, 2020.

3. Wei Xiao'an, It is spring after severe winter. http://www.chinala.org.cn 
4. Manila World Tourism Declaration, a programmatic document on tourism development adopted by the World Tourism Organization at the World Tourism Conference held in 1980. 